\title{
LES simulation and experimental validation of the unsteady aerodynamics of blunt wind turbine airfoils
}

\author{
Wang, Guofu; Zhang, Lei; Shen, Wen Zhong
}

Published in:

Energy

Link to article, DOI:

10.1016/j.energy.2018.06.093

Publication date:

2018

Document Version

Peer reviewed version

Link back to DTU Orbit

Citation (APA):

Wang, G., Zhang, L., \& Shen, W. Z. (2018). LES simulation and experimental validation of the unsteady aerodynamics of blunt wind turbine airfoils. Energy, 158, 911-923. https://doi.org/10.1016/j.energy.2018.06.093

\section{General rights}

Copyright and moral rights for the publications made accessible in the public portal are retained by the authors and/or other copyright owners and it is a condition of accessing publications that users recognise and abide by the legal requirements associated with these rights.

- Users may download and print one copy of any publication from the public portal for the purpose of private study or research.

- You may not further distribute the material or use it for any profit-making activity or commercial gain

- You may freely distribute the URL identifying the publication in the public portal 


\section{Accepted Manuscript}

LES simulation and experimental validation of the unsteady aerodynamics of blunt wind turbine airfoils

Guofu Wang, Lei Zhang, Wen Zhong Shen

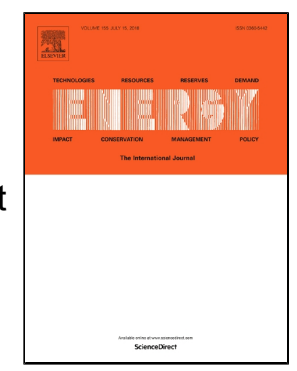

PII: $\quad$ S0360-5442(18)31158-7

DOI: $\quad 10.1016 / j$.energy.2018.06.093

Reference: $\quad$ EGY 13135

To appear in: $\quad$ Energy

Received Date: $\quad 23$ January 2018

Accepted Date: $\quad 14$ June 2018

Please cite this article as: Guofu Wang, Lei Zhang, Wen Zhong Shen, LES simulation and experimental validation of the unsteady aerodynamics of blunt wind turbine airfoils, Energy (2018), doi: 10.1016/j.energy.2018.06.093

This is a PDF file of an unedited manuscript that has been accepted for publication. As a service to our customers we are providing this early version of the manuscript. The manuscript will undergo copyediting, typesetting, and review of the resulting proof before it is published in its final form. Please note that during the production process errors may be discovered which could affect the content, and all legal disclaimers that apply to the journal pertain. 


\section{LES simulation and experimental validation of the}

\section{2 unsteady aerodynamics of blunt wind turbine airfoils}

3 Guofu Wang ${ }^{1}$, Lei Zhang ${ }^{2 *}$, Wen Zhong Shen ${ }^{3}$

41 Liao Ning Shihua University, Fushun 113001, China

52 Institute of Engineering Thermophysics, Chinese Academy of Sciences, Beijing 100190, China

63 Department of Wind Energy, Technical University of Denmark, 2800 Lyngby, Denmark

7 * Correspondence: zhanglei@iet.cn; Tel.: +86-10-82543132

\section{Abstract:}

9 In order to investigate the unsteady performance of blunt wind turbine airfoils caused by

10 boundary layer separation and wake eddies, this paper studies the aerodynamic performance by

11 large eddy simulation (LES) and wind tunnel experiment at a Reynolds number of $2.62 \times 10^{\wedge} 5$. The

12 blunt airfoils are obtained by enlarging the trailing edge of the DU 91-W2-250 airfoil to 6\% and

$1310 \%$ chords symmetrically on both pressure and suction sides of the airfoil. The simulation was

14 carried out with the incompressible finite-volume Navier-Stokes code EllipSys3D; and, the

15 experiment was done in a wind tunnel with a cross-section of $0.5 \mathrm{~m} \times 0.5 \mathrm{~m}$ by measuring the 16 surface pressure and wake velocities using ESP-64HD pressure scanner and TSI hot-wire 17 anemometer. The unsteady wake was captured by hot-wire in the wind tunnel, and LES with 18 EllipSys3D. Both experiment and LES show that the spectrum of aerodynamic forces has a 19 broadband nature which is in coincidence with the wake eddies, implying that the unsteady 20 Kármán vortex sheet is the driving mechanism of the force fluctuation. Moreover, the trailing edge

21 size affects the separation bubbles and transition process in the boundary layer. It shows that the 22 boundary layer near the leading edge is unstable in the spanwise direction, which is characterized 23 by low frequency waves. 
24 Keywords: blunt airfoil; wake; unsteady; transition; large eddy simulation; experiment

25 Nomenclature

$26 \mathrm{Cd}=$ drag coefficient of airfoil

$27 \mathrm{Cl}=$ lift coefficient of airfoil

$28 C_{p}=$ pressure coefficient

$29 \operatorname{Re}=$ Reynolds number

$30 \mathrm{c}=$ chord length

$31 d=$ reference length

$32 f=$ frequency

$33 h^{\prime}=$ wake width

$34 \bar{p}=$ average pressure

$35 s=$ spanwise length of airfoil model

$36 t=$ time

$37 \bar{u}_{i}$ or $\bar{u}_{j}=$ time-averaged velocity component

$38 u_{\mathrm{s}}=$ velocity at separation

$39 u_{\infty}=$ free stream velocity

$40 u=$ velocity in $x$ direction

$41 v=$ velocity in $\mathrm{y}$ direction

$42 w=$ velocity in $z$ direction

$43 x=$ spanwise coordinate

$44 x_{i}$ or $x_{j}=$ coordinates in the NS equations, typically refering to $\mathrm{x}, \mathrm{y}$, and $\mathrm{z}$ in Cartesian 
$47 z=$ streamwise coordinate

$48 \quad \alpha=$ angle of attack

$49 \rho=$ density of fluid

$50 v \quad=\quad$ kinematic viscosity of fluid

$51 \tau_{i j}=$ shear stress

\section{Introduction}

With the development of wind energy industry, the size of wind turbine rotors increases gradually and the maximum capacity of a single commercial wind turbine has gone up to $8 \mathrm{MW}^{[1]}$. Large scale rotor blades should be manufactured strongly enough to bear both aerodynamic and structural loads. Blunt-trailing-edge airfoils have potential advantages due to their larger sectional area and high lift coefficient, especially when they are used at the inboard section of blade ${ }^{[2,3]}$. However, the shedding vortices in the wake may cause a base drag, unsteadiness and vortex shedding noise ${ }^{[4,5]}$. The present study mainly focused on the unsteady aerodynamics due to the vortex street in the wake, which was primarily studied in aeronautic wing applications ${ }^{[6]}$. In 1987 , Law and Gregorek evaluated a truncated airfoil for the application on large wind turbines and concluded that the truncated airfoil had a higher maximum lift, higher lift curve slope, lower drag at higher lift coefficient, and higher chordwise force coefficient than sharp-trailing-edge airfoils with a similar thickness ${ }^{[7]}$. Additionally, Sato and Sunada (1995) found that the maximum lift-todrag ratio could be increased by cutting off the trailing edge of airfoils ${ }^{[8]}$, while Iwasaki et al. (1997) provided further verification on the lift curve slope which is higher than both the original airfoil and sharp airfoils with the same thickness ${ }^{[9]}$. In 2003, Standish and van Dam investigated the aerodynamic performance of blunt-trailing-edge airfoils and indicated that the lower adverse pressure gradient could decrease the sensitivity to premature boundary-layer transition, i.e. 
insensitive to leading edge contamination ${ }^{[10]}$. Following those topics, Baker et. al. conducted experimental studies and verified that blunt-trailing-edge airfoils were insensitive to leading edge contaminations and the drag increase was caused by the base drag in the wake ${ }^{[11]}$. The detailed researches on blunt airfoils and blades by van Dan team (at University of California Davis) were referred to references [12-18]. Moreover, similar work was done by T. Zhang et al. based on computational fluid dynamics method ${ }^{[19]}$.

On the blunt airfoils for wind turbine application, the research topics are strongly diversity, including such as aerodynamic performance, simulation methods, design methods, application on blades, and so on. In 2006, Christopher et. al. studied the performance of blunt airfoils with computational fluid dynamics and showed that the DES method did not predict the transition and separation along the airfoil surface while the HRLES method did ${ }^{[20]}$. The authors investigated the aerodynamic performance of blunt airfoils affected by vortex generators ${ }^{[21]}$. As for design methods, in 2003, Standish and van Dam found that symmetrically adding thickness along the baseline airfoils is better than the cutting off method ${ }^{[10]}$, which was also proofed by Murcia and Pinilla in 2011 ${ }^{[22]}$. Moreover, the optimization of blunt airfoil shape using a genetic algorithm should produce even better airfoils meeting specific objectives ${ }^{[23]}$. Except researching the aerodynamic performance of airfoils, the influence of blunt airfoils on rotor blade was studied by Lee et. al. based on the benchmark blade, i.e., NREL Phase VI blade ${ }^{[24]}$. Additionally, it has been studied that flatback, i.e., blunt, design does not impede rotational augmentation of aerodynamic performance on rotor blades $^{[25]}$. The results showed that the blunt trailing edge airfoil helps to improve both structural and aerodynamic performance of the blade. Conclusively, in wind energy applications studies were mainly focused on the steady aerodynamics and the overall characteristics.

Due to shedding vortices from the blunt trailing edge, the aerodynamic performance of blunt airfoils is unsteady. The shedding vortices adversely increase the base drag and lead to unfavorable noise and aeroelastic problems ${ }^{[26]}$. In 2011, the authors primarily studied the unsteady characteristics of blunt airfoils and described the unsteady characteristics of lift and drag 
coefficients of blunt airfoils[27]. Similar conclusions were put up by Xu et. al. ${ }^{[28]}$. In 2015, Bangga et. al. investigated the unsteady characteristics of flow over thick blunt airfoils and suggested a new definition of Strouhal number ${ }^{[29]}$. Because the rotor operates in unsteady conditions and the fatigue loads are caused by unsteady forces, more efforts should be paid on unsteady aerodynamics of blunt airfoils and blunt blades, which is the motivation of the present study.

In this paper, the unsteady aerodynamics and boundary layer instability of blunt airfoils were studied by three dimensional LES based on the CFD solver EllipSys3D[30]. Meanwhile, measurements with ESP-64HD pressure scanner and TSI hot-wire anemometer were carried out to compare and verify the numerical method and shedding frequency of vortex sheet in the wake.

\section{Methods}

\subsection{Large eddy simulation}

Due to the blunt trailing edge, the vortex shedding downstream and in the boundary layer is expected to dominate the flow characteristics. Since Reynolds Averaged Navier-Stokes (RANS) simulation is not accurate enough to capture broad scales of eddies in the flow field, large eddy simulation is applied on this research issue. These simulations are based on a CFD solver, EllipSys3D, developed at Wind Energy Department of Technical University of Denmark. For more details about the numerical techniques, the reader is referred to references [30-33].

The code is based on a multi-block/cell-centered finite volume discretization of steady/unsteady incompressible Navier-Stokes equations ${ }^{[34-36]}$ in primitive variables (pressure and velocity). In this code, the momentum equations are discretized by a second-order backwarddifferentiation scheme in time and second-order central differences in space, while the convective terms are discretized by the QUICK upwind scheme ${ }^{[37]}$. The code is programmed using the multiblock topology; therefore, it is easily parallelized using message-passing interface (MPI). The filtered incompressible Navier-Stokes equations, turbulent stresses and eddy viscosity equations are solved to obtain the turbulent flow data. 


$$
\frac{\partial \bar{u}_{i}}{\partial x_{i}}=0
$$

$$
\frac{\partial \bar{u}_{i}}{\partial t}+\bar{u}_{j} \frac{\partial \bar{u}_{i}}{\partial x_{j}}=-\frac{1}{\rho} \frac{\partial \bar{p}}{\partial x_{i}}+\frac{\partial}{\partial x_{j}}\left(v \frac{\partial \bar{u}_{i}}{\partial x_{j}}\right)+\frac{1}{\rho} \frac{\partial \tau_{i j}}{\partial x_{j}}
$$

used in this paper is the mixed-scale turbulence model ${ }^{[37]}$.

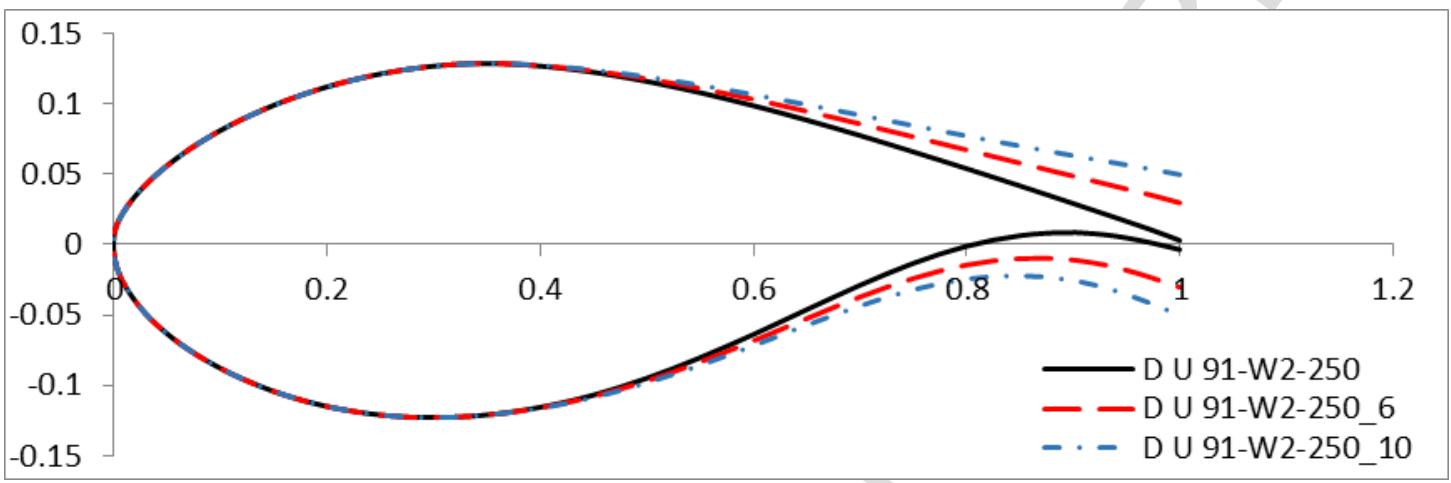

The baseline airfoil examined in this study is DU 91-W2-250 with a maximum thickness to

128 chord ratio of $25 \%{ }^{[38]}$. The trailing edge of this airfoil is enlarged from the original thickness of $0.65 \% c$ to $6 \% c$ and $10 \% c$ by symmetrically adding thickness on both sides. They are denoted as DU 91-W2-250_6 and DU 91-W2-250_10 respectively, as shown in Figure 1.

The computational domain is shown in Figure 2, which is the same as the wind tunnel testing section to verify LES results against measurements directly. A multi-block structured conformal mesh is used in the simulations with 60 blocks of $64 \times 64 \times 64$. In the flow region with airfoil, the Omesh topology is employed with 512 grid points on the airfoil, i.e., the averaged spacing in the chordwise direction equaling 0.0041c. The spanwise grid number is 128 based on previous experiences ${ }^{[37]}$, and the averaged spacing in spanwise equals 0.026c. The maximum Equiangle Skew of grid cells is 0.57 which appears at the trailing edge. The smallest wall normal distance is $10^{\wedge}-5$ so that $\mathrm{y}^{+}$is less than 1 at a Reynolds number of $3 \times 10^{\wedge} 5$.

In simulations, velocity inlet with no perturbations and outlet boundary conditions are applied, as well as the slip wall boundary condition on the tunnel walls. The simulations were 
141 conducted in dimensional system and the inflow velocity was set as $30 \mathrm{~m} / \mathrm{s}$. The simulation period

142 lasted at least $5 \mathrm{~s}$ with a time step of $0.0001 \mathrm{~s}$. Instantaneous flow fields are saved synchronically

143 with the averaged flow field; and moreover, typical time history data are recorded ahead the

144 leading edge, as well as inside the boundary layer on the suction surface and in the wake.

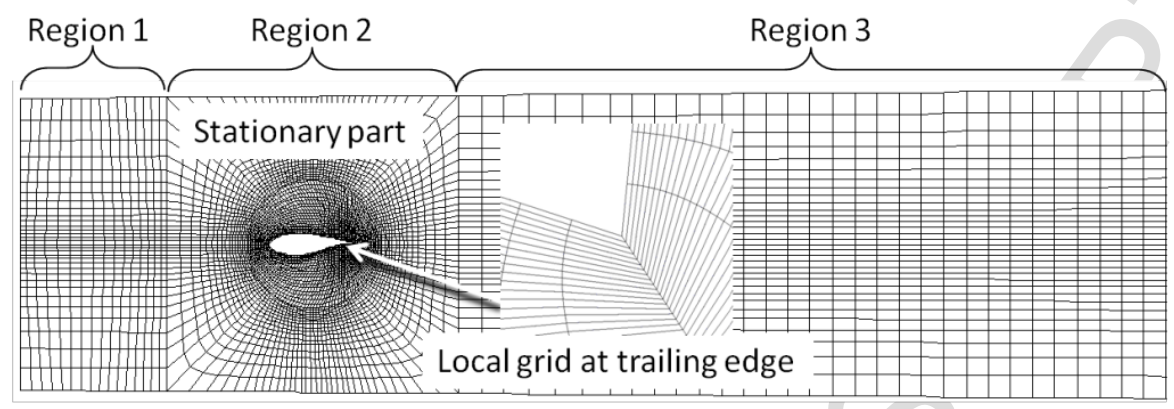

149 Academy of Sciences) wind tunnel with a cross-sectional dimension of $0.5 \mathrm{~m} \times 0.5 \mathrm{~m}$ and a tunnel

150 length of $2.0 \mathrm{~m}$. The setup of airfoil model in this wind tunnel is shown in Figure 3. The ceiling and

151 bottom walls of the test section are parallel but the side walls are tapered with an angle of 0.8

152 degrees to compensate for boundary layer growth. The wind tunnel was calibrated before

153 measurements using a hot-wire anemometer and other necessary apparatus. The slope of static

154 pressure drop and turbulence intensities depending on wind speeds are shown in Table 1 . The

155 turbulence intensity at $30 \mathrm{~m} / \mathrm{s}$ is less than $1.6 \%$ and the static pressure coefficient drop is less than

$156 \quad 1.8 \%$ per meter along the axis of wind tunnel. 


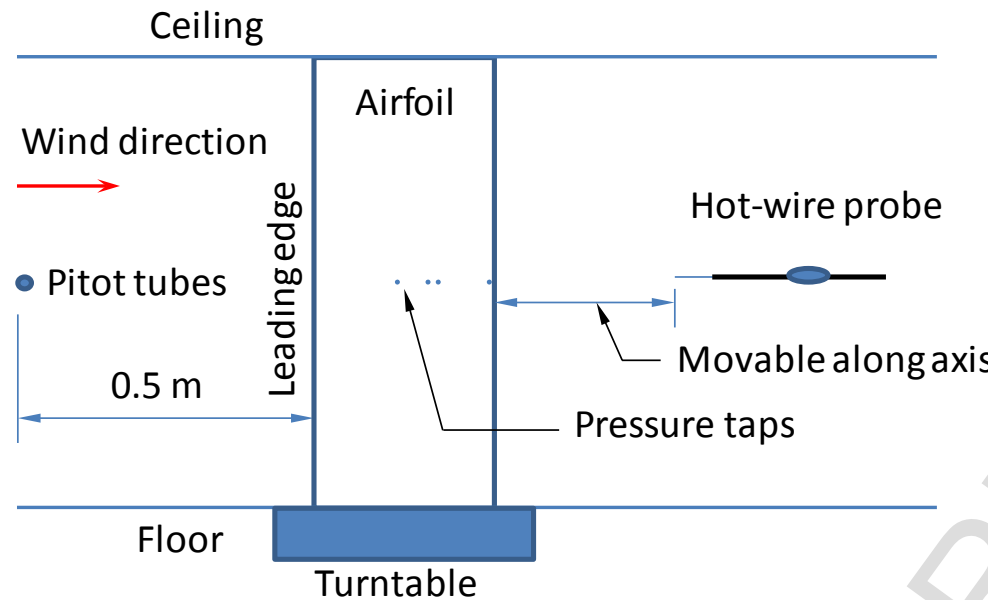

Figure 3 Setup of an airfoil model in the IET low speed wind tunnel

Table 1 parameters of the wind tunel

\begin{tabular}{lccc}
\hline Wind speed $(\mathrm{m} / \mathrm{s})$ & 8.4 & 21.8 & 34.8 \\
\hline Slope of static pressure coefficient drop $(1 / \mathrm{m})$ & - & 0.0180 & 0.0134 \\
& & & \\
Turbulence intensities (\%) & 0.133 & 0.141 & 0.156
\end{tabular}

161 stepping motor. The angle of attack can be controlled with a precision of \pm 0.05 degrees. The 162 spanwise width of the model is $0.496 \mathrm{~m}$, leaving a gap of $0.004 \mathrm{~m}$ from the ceiling wall. The chord

163 length of the test models is 0.15 m producing a minimum solid blockage of $7.5 \%$. As an example,

164 reliable results were obtained with the minimum blockage of $8.3 \%$ in the similar test ${ }^{[39]}$. Because the 165 same airfoil models with tunnel walls were applied in LES, the obtained data can be compared 166 directly without corrections of tunnel walls and blockage.

167 The experiment was carried out at a Reynolds number of $R e=2.62 \times 10^{\wedge} 5$. The corresponding 168 velocity is $30 \mathrm{~m} / \mathrm{s}$, measured by Pitot tubes at $0.5 \mathrm{~m}$ upstream from the turning axes of the testing 169 model. Pressure taps (48 50 depending on specific models) were mounted in the middle section of 170 testing models, whose distribution was pre-optimized based on the pressure distribution calculated 171 by $\mathrm{XFOIL}{ }^{[40]}$. The maximum measuring range of pressure sensors is \pm 1.0 PSI with a tolerance of $172 \pm 0.05 \%$ FS. On the other hand, the hot-wire sensor is calibrated before the measurement with an 173 error of less than $\pm 0.3 \%$. 


\section{Validation and comparison of the two methods}

The experimental data should be verified itself and then used for validation of numerical simulations. First, the repeated measurements are compared for the DU91-W2-250 and DU91-W2$250 \_6$ at an angle of attack of $0^{\circ}$. Second, the lift and drag coefficients are compared between numerical simulations and measurements; and, the effect of spanwise grid density on drag coefficient is also examined in this part. Third, pressure distributions of all the three airfoil models are compared. Finally, the simulated frequency spectrum of velocity in the wake is compared to measurement; and meanwhile, the grid stretching effect on spectral characteristics is discussed.

\subsection{Validation of experiment by repeats}

The distributions of surface pressure are compared in Figure 4 a) and b) where the repeated measurements were carried out at an airspeed of $20 \mathrm{~m} / \mathrm{s}$. Different tests are numbered as "test1", "test2", and "test3" in the figure. It shows that the pressure distributions basically match each other with only very small differences. The differences are less than 3.5\% for the DU 91-W2-250 airfoil. A similar validation is carried out for the DU 91-W2-250_6 airfoil, showing that maximum differences are less than $2.2 \%$.

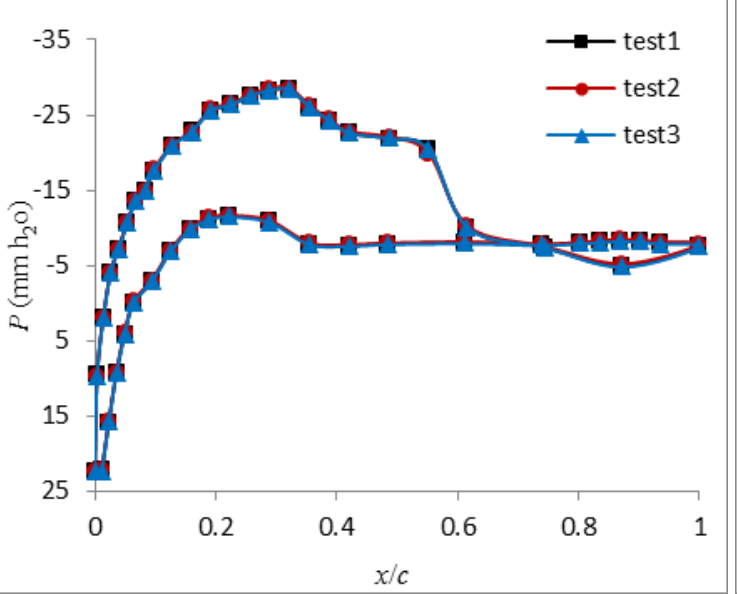

a)

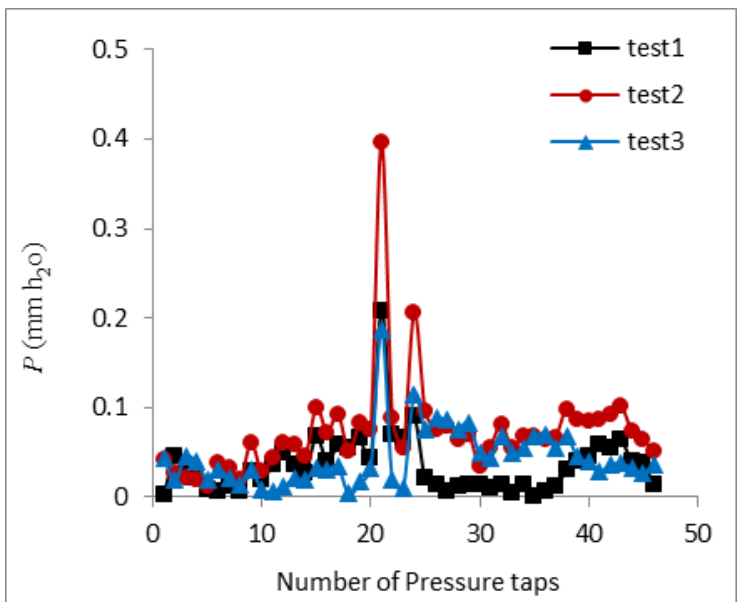

b)

Figure 4 Comparison of pressure distribution from the repeated measurements. a) Pressure distribution of DU 91-W2-250; b) Difference between tests and their average values 


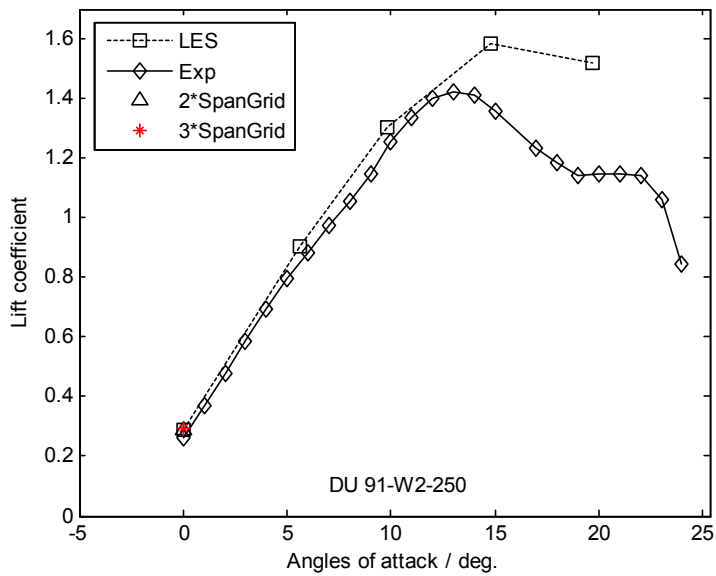

a)

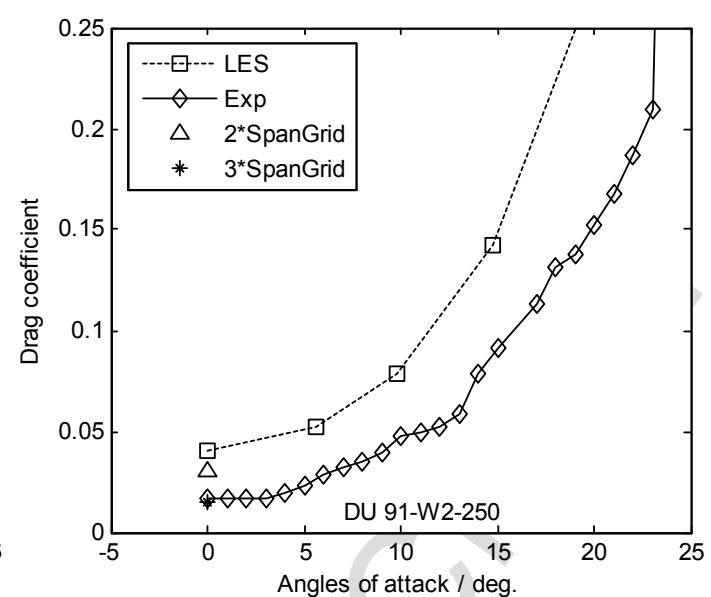

b)

Figure 5 Comparisons of force coefficients at $R e=2.62 \times 10^{\wedge} 5$. a) Lift coefficient of DU 91-W2-250, b) Drag

coefficient of DU 91-W2-250.

Figure 5 shows the comparisons of lift and drag coefficients of DU 91-W2-250 predicted by LES and measured by pressure scanner. It indicates that the lift from LES is in better agreement with overestimates the lift. Drag coefficient in simulation is strongly affected by spanwise grid density, but the lift coefficient varies slightly with less difference. Refinement of the spanwise grid is necessary if the drag simulation is the key concern ${ }^{[37]}$. To test the influence, the spanwise grid number was refined by two times and three times for the airfoil model DU 91-W2-250. It was found that the drag coefficient firstly dropped to 0.0304 (two-times refined) and then to 0.0154 (three-times refined), much close to the experimental value of 0.017 .

\subsubsection{Comparison of pressure distributions}

Figure 6 shows comparisons of time-averaged surface pressure distributions at the mid-span of

210 airfoils at an angle of attack of $10^{\circ}$. The pressure distributions on the pressure side match together

211 as well as the suction peaks. And, LES captures the pressure platform and the followed pressure

212 drop on both sides of airfoil surface. In addition, the pressure distribution at other angles of attack

213 is also compared and the difference is that the area enclosed by pressure curves from LES is slightly 
215 are slightly larger than that from experiment.
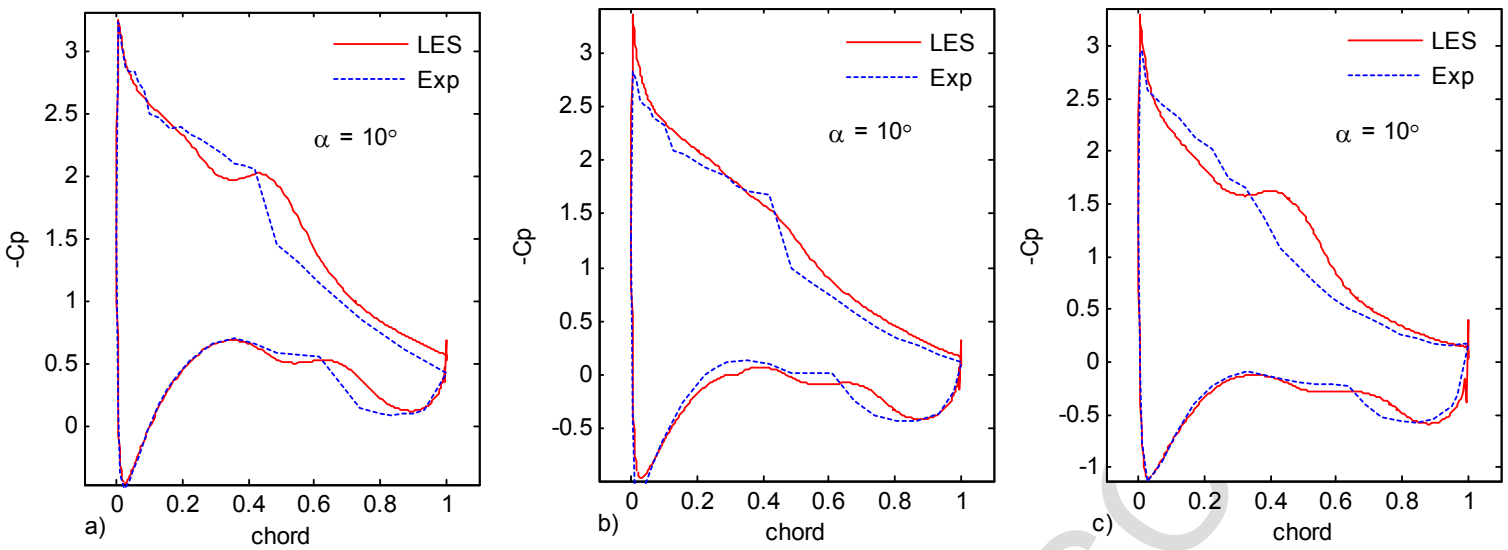

Figure 6 Comparison of time-averaged pressure distribution at $\alpha=10^{\circ}$ and $\operatorname{Re}=2.62 \times 10^{5}$. a) DU 91-W2-250,

b) DU 91-W2-250_6, c) DU 91-W2-250_10

\subsubsection{Comparison of velocity frequency in the wake}

In numerical simulations, the grid stretching has an important effect on the maximum calculated frequency because a coarse grid will smooth out small-scale vortices. Figure 7 shows the effect of grid stretching on the highest frequency that can be captured by the mesh. The spectra are smoothed by a filter to clearly show the trend. The circles in the figure show the spectral energy near the leading edge where a fine mesh is used. The stars show the spectral energy in the wake where a coarse mesh is used. It shows that in the boundary layer with a fine mesh we can capture small scale vortices in the inertial sub-range. The highest frequency that can be distinguished is as high as $5000 \mathrm{~Hz}$. On the other hand, the coarse mesh in the wake can only capture vortices with frequencies no more than $600 \mathrm{~Hz}$.

In the experiment, the velocity frequency in the wake was acquired by a hot-wire probe with a sample frequency of $1000 \mathrm{~Hz}$. The measured peak value of velocity frequency in the wake of DU 91are $440.1 \mathrm{~Hz}$ and $323.2 \mathrm{~Hz}$ with errors of $0.1 \%$ and $4.7 \%$, respectively. As an example, the 
235 frequencies are basically in good agreement.

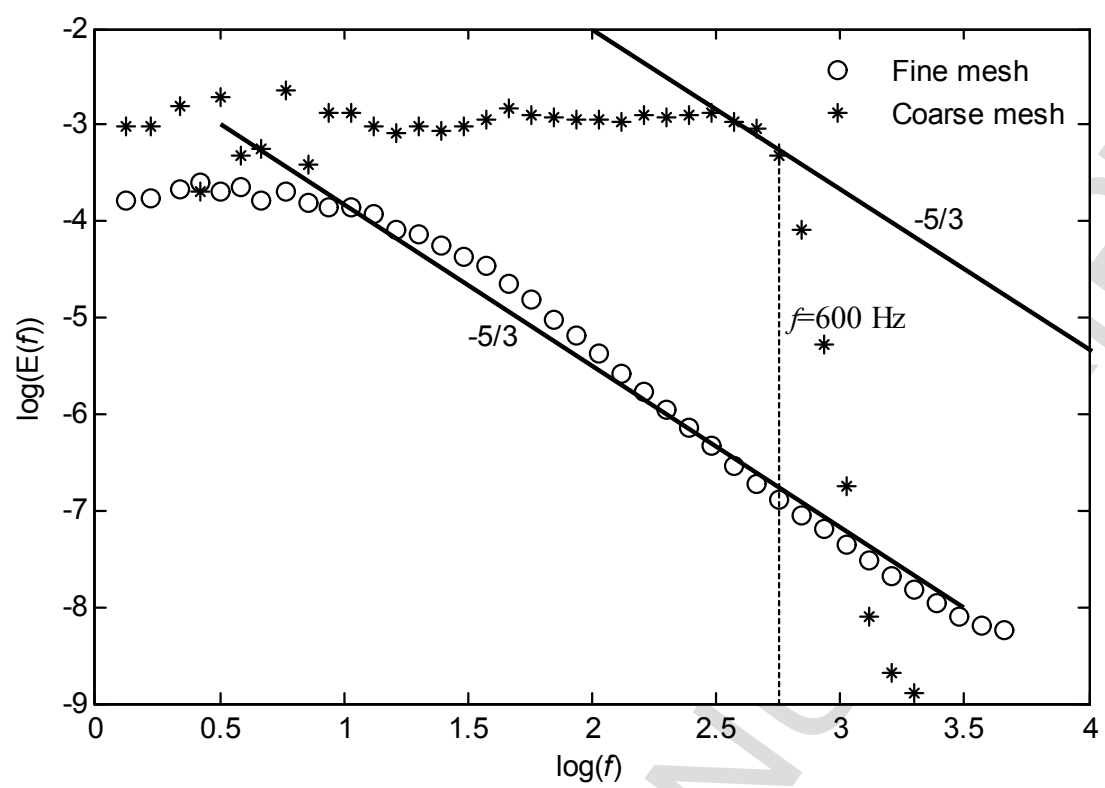

Figure 7 Effect of grid density on spectral energy of velocities

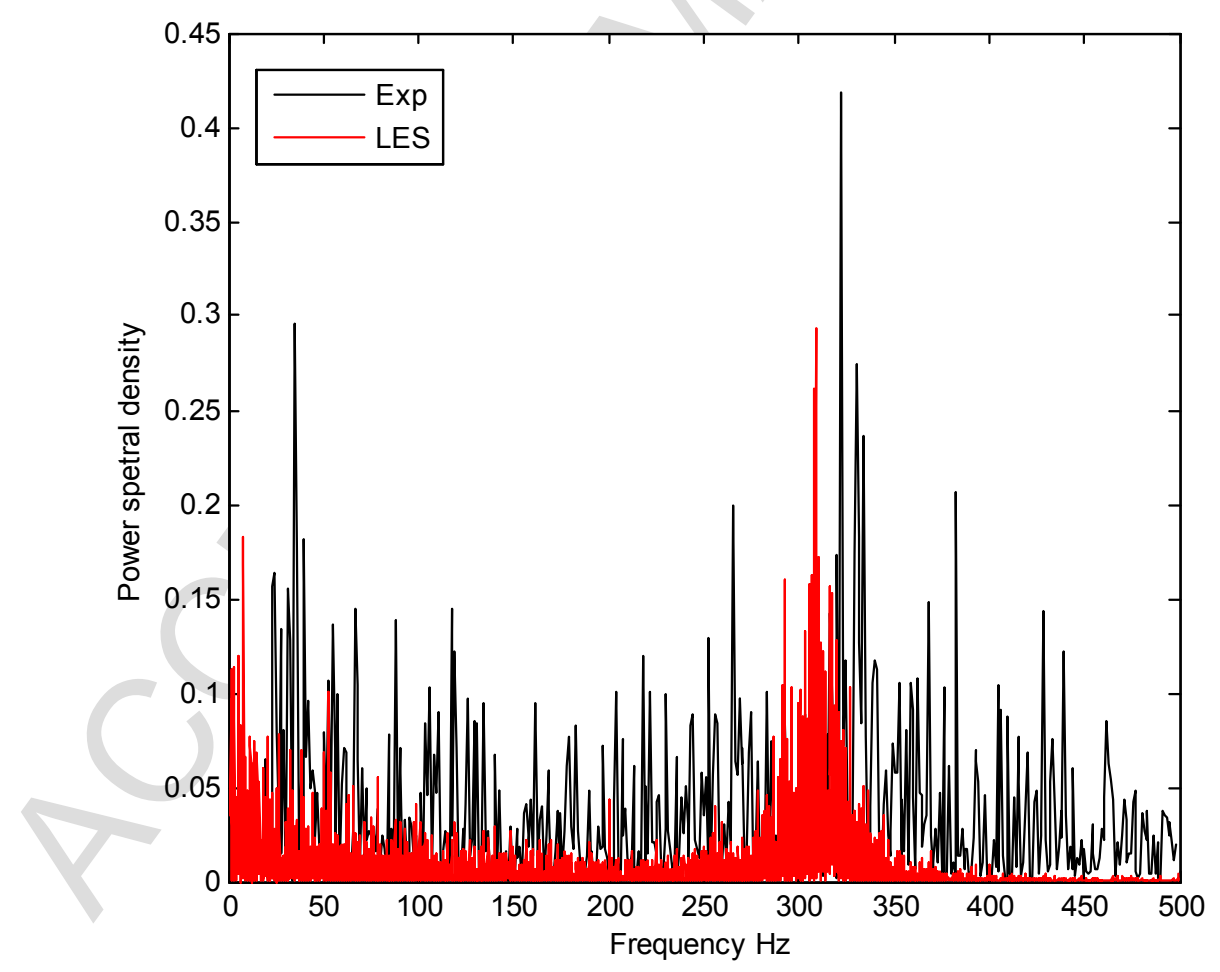


The main objective of this study is to examine the unsteady dynamics of blunt airfoils by LES

242 and experimental methods because of the lack of data in literature. The first issue is the spectrum characteristics of forces and velocities. Time signals of force coefficients are analyzed by spectral analysis to overlook the unsteady characteristics of blunt airfoils. Then the dominant frequencies at different angles of attack are compared. The relationship between the vibration of velocities and the fluctuation of airfoil forces is illustrated by comparing their spectra. The second issue is about the instability of boundary layer on blunt airfoils. Boundary layer separation bubbles are examined as well as the influence of trailing edge thickness and angle of attack on them. By comparing the velocity frequency in the boundary layer the development of T-S waves is illustrated. Additionally, the spanwise modes of velocity are analyzed at the end of this issue.

\subsection{Spectral analysis}

\subsubsection{Fourier analysis of lift coefficients}

Large eddy simulations get vibrating forces, as well as velocities in the flow field, containing many small fluctuations, which are different from URANS simulations containing a single frequency fluctuation $\left.{ }^{[27} 28\right]$. The dominant frequency can be worked out by applying the fast Fourier transform (FFT) on time signals. Taking the lift signal of DU 91-W2-250_6 at Re $=2.62 \times 10^{\wedge} 5$ and $\alpha=0^{\circ}$ as an example, the time signal shows no regulation but the lift spectrum shows obviously the dominant frequency appearing at about $451 \mathrm{~Hz}$, as shown in Figure 9. By a similar analysis, the dominant frequency of DU 91-W2-250_10 at the same condition is $308 \mathrm{~Hz}$. The peak frequency observed for the lift coefficient is relative with the vortex shedding in the wake because of the absence of external perturbation. However, no characteristic frequency is captured for DU 91-W2250 because the trailing thickness is small and the mesh in the wake region is not fine enough. 

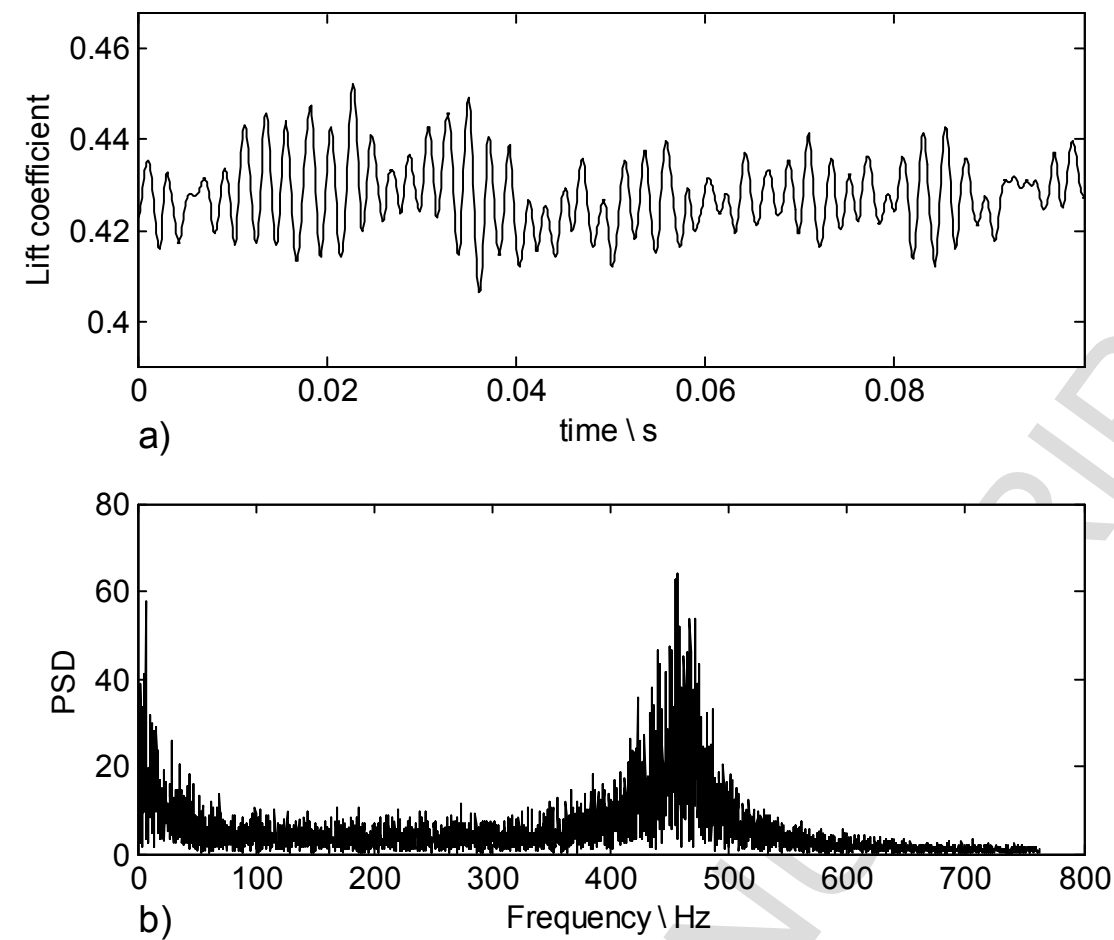

Figure 9 Fourier analysis on the lift coefficient of DU $91-W 2-250 \_6$ at $\operatorname{Re}=2.62 \times 10^{\wedge} 5$ and $\alpha=0^{\circ}$.

Specific characteristic frequencies of the lift coefficient at various angles of attack are shown in

Table 2. The dominant frequencies for DU 91-W2-250_6 and DU 91-W2-250_10 before stall are about $450 \mathrm{~Hz}$ and $330 \mathrm{~Hz}$, respectively. After stall, there are large separated vortices from the airfoil body and the characteristic frequency decreases a lot, which is in agreement of the previous researches ${ }^{[28]}$.

Table 2 Characteristic frequency of $C l$ at different angles of attack and $\operatorname{Re}=2.62 \times 10^{\wedge} 5$

\begin{tabular}{lccccr}
\hline Angles of attack (deg) & 0 & 5 & 10 & 15 & 20 \\
\hline DU 91-W2-250_6 & 451 & 447 & 457 & - & - \\
DU 91-W2-250_10 & 308 & 336 & 340 & 30 & 31 \\
\hline
\end{tabular}

Eddies shed from the trailing ledge of a blunt airfoil, induce vibrations on aerodynamic forces.

272 Figure 10 shows the spectra of the $y$-direction velocity at different locations in the wake of the DU

273 91-W2-250_6 airfoil at $\alpha=0^{\circ}$. The peak frequency of the velocity is about $440 \mathrm{~Hz}$, smaller than the

274 peak frequency of the corresponding lift coefficient as shown in Table 2 and Figure 10. The reason is 
that the lift contains all the effects of three-dimensional vortices in the wake, but the velocity spectrum represents only one point at middle span in the wake. The similar phenomenon was

277 found by Huang and Lin, whoes results showed that the frequency of velocity varies with the span

278 location in the wake $\mathrm{e}^{[42]}$. Therefore, the difference between the velocity and lift frequencies is 279 reasonable. As the monitoring point moves downstream, the amplitude of vibration decreases and 280 the peak frequency disappears in the far wake region. The turbulence dissipation plays an 281 important part in decrease of vortices, as well as the cut-off effect of the coarse grid in the far wake 282 region.

283 Further examinations on another blunt airfoil DU 91-W2-250_10 show that large shedding 284 vortices spread farther downstream than small vortices in the wake. The peak frequency can also be 285 found at $3.4 c$. The peak frequency of the vortex shedding at $\alpha=0^{\circ}$ is about $313 \mathrm{~Hz}$ which is slightly 286 larger than that of the lift coefficient in Table 2, providing an additional evidence that the frequency 287 of velocity in wake doesn't equal to that of the lift coefficient. Furthermore, it can be found that the 288 peak frequency of shedding vortices in the wake of DU 91-W2-250_10 is smaller than that of DU 91289 W2-250_6 due to the increase in trailing edge thickness. Therefore, the dominant frequency of the 290 lift coefficient of DU 91-W2-250_10 is correspondingly smaller than that of DU 91-W2-250_6. 


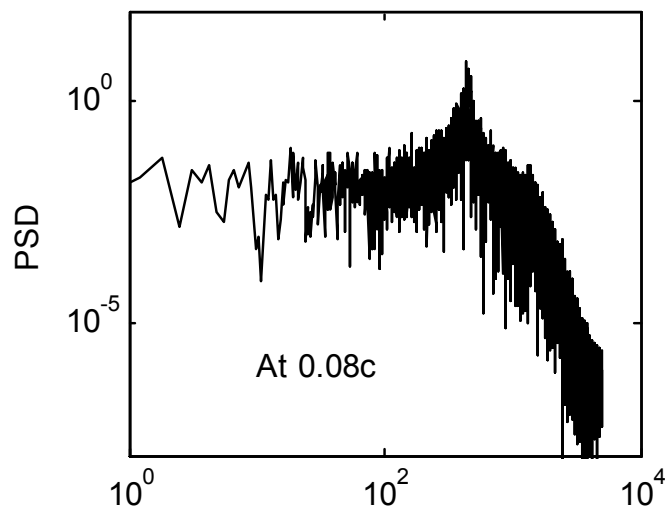

a)

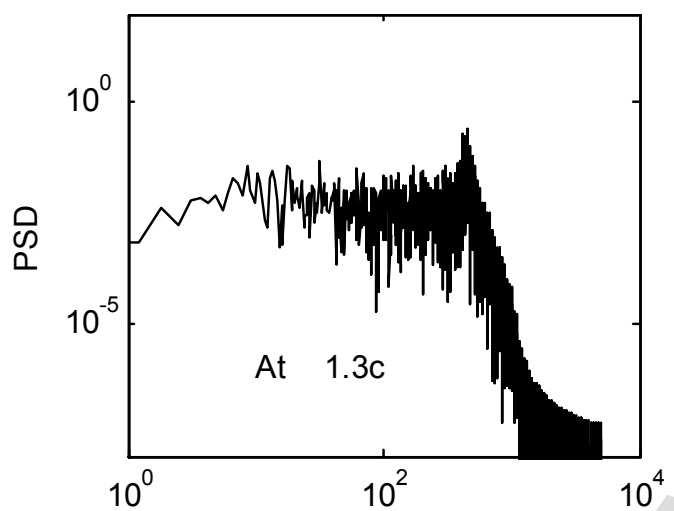

c)

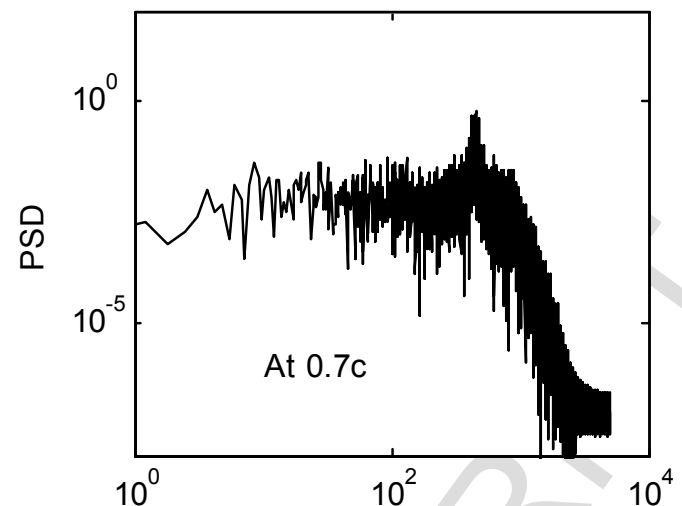

b)

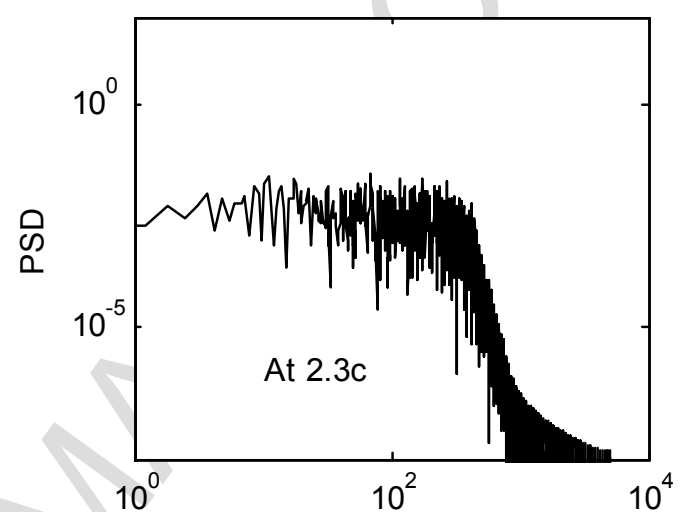

d) Frequency $\mathrm{Hz}$

Figure 10 Velocity spectra in the wake of the airfoil model DU 91-W2-250_6 at $\operatorname{Re}=2.26 \times 10^{5}$ and $\alpha=0^{\circ}$, a) at

The above results show that the fluctuation of aerodynamic forces depends on the vortex

shedding in the wake region but the peak frequencies may be slightly different between forces and velocities at a specific point downstream.

\subsection{Boundary layer instability}

\subsubsection{Boundary layer separation}

In Figure 11 the instantaneous streamlines at mid span of airfoil models are plotted at two different angles of attack, i.e., $\alpha=0^{\circ}$ and $\alpha=10^{\circ}$. Because the Reynolds number is low, the boundary layer on airfoil models separates even at $\alpha=0^{\circ}$. For the DU 91-W2-250 airfoil, small separation 
303 separation bubble on the suction surface approaches the leading edge when increasing the angle of

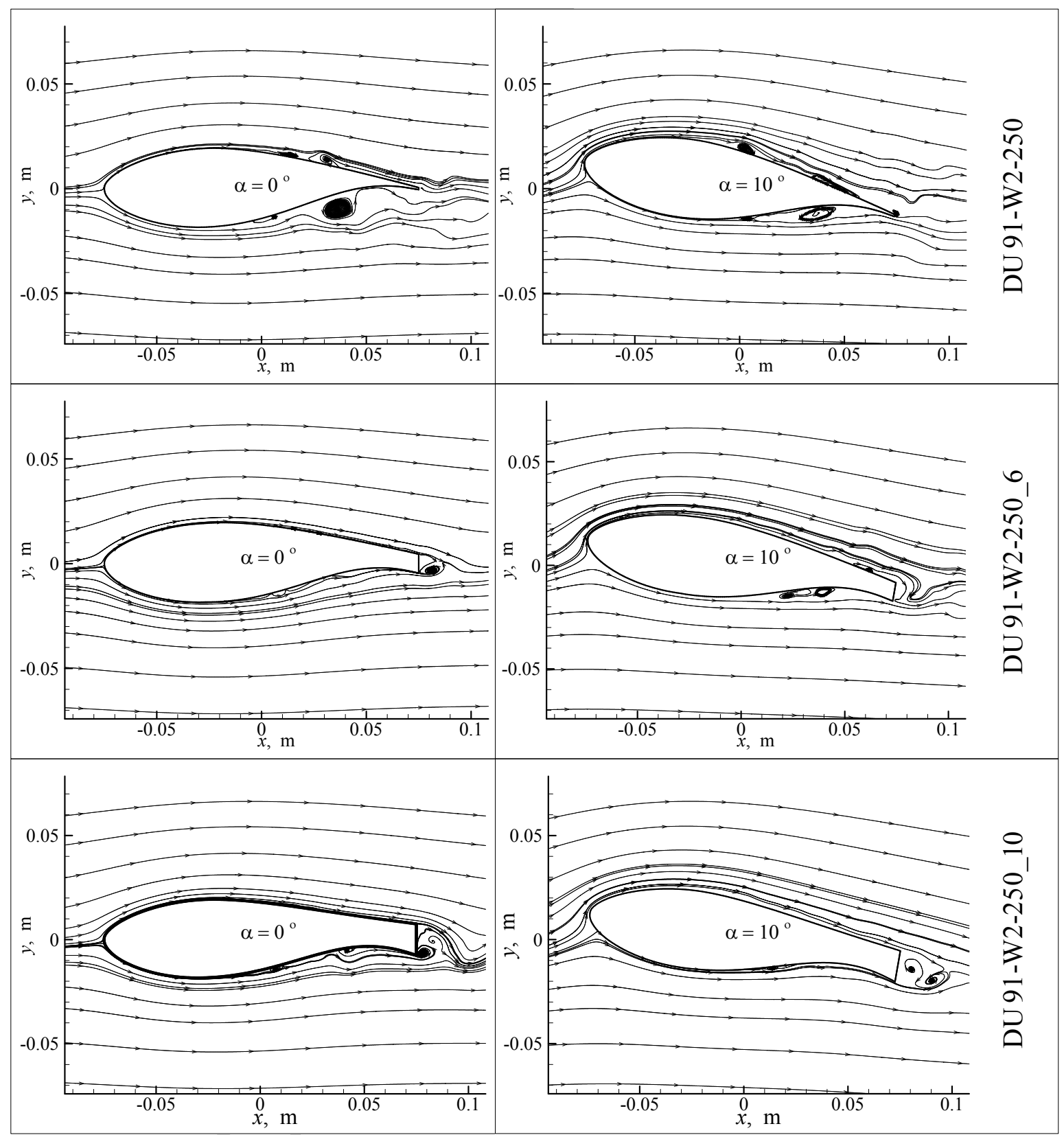

306 attack, while it moves towards the trailing edge on the pressure surface. At large angles of attack

307 the entire boundary layer separates from the leading edge on the suction surface indicating that the

308 airfoil is undergoing stall. Compared with instantaneous results, the time-averaged flow structures

309 are shown in Figure 12, which are much more different from the instantaneous flow field. The

310 transient discrete shedding vortices in the boundary layer merge together into a long and thin 
311 separation bubble in the averaged flow field, and it exists at all angles of attack simulated. The

312 separation flow reattaches to the surface of airfoil again when the laminar-turbulent transition

313 manages to increase the momentum into the boundary layer that overcomes the adverse pressure

314 gradient.

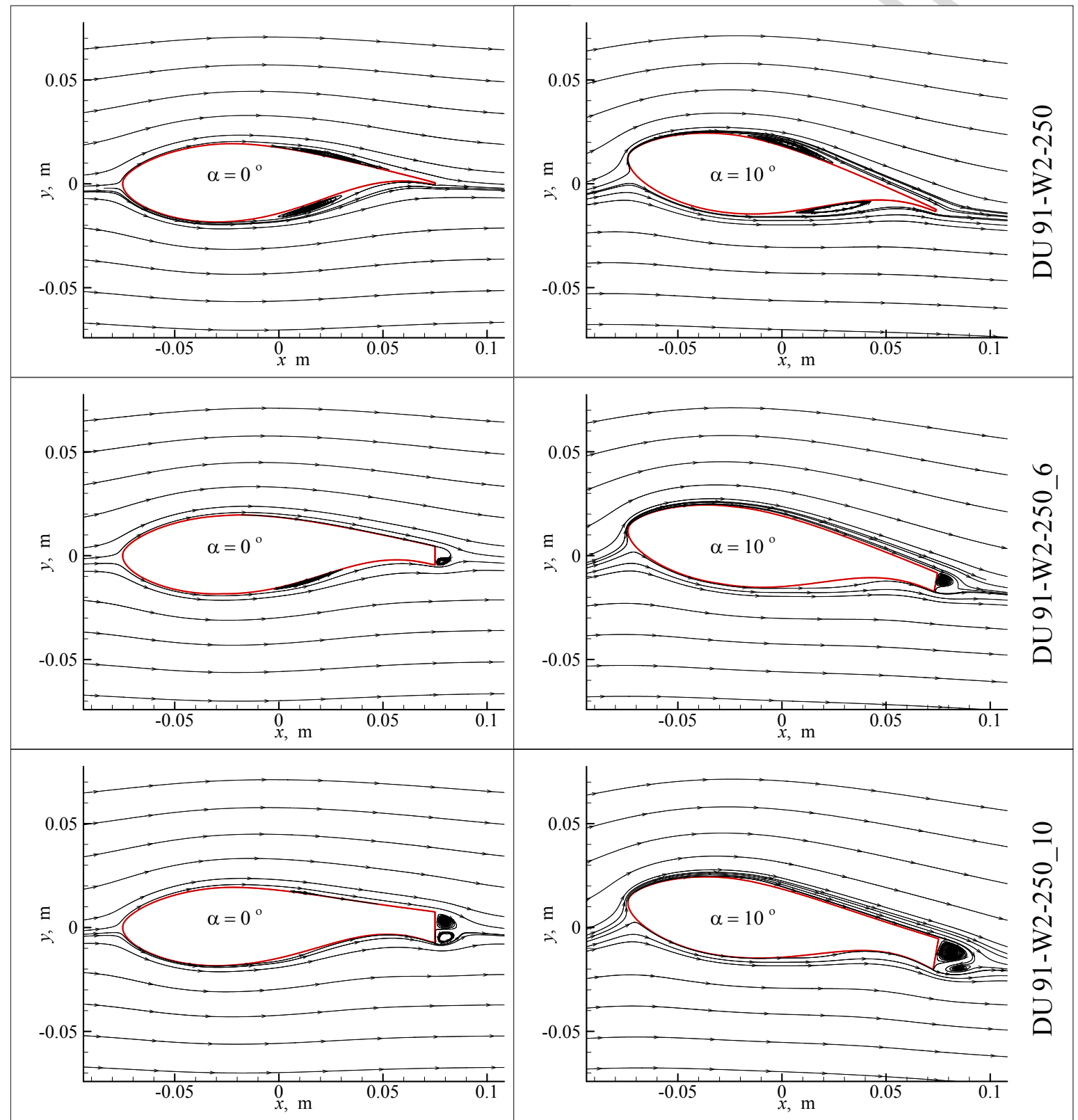

Figure 12 Time-averaged flow field at mid span shown by streamlines at $\operatorname{Re}=2.62 \times 10^{5}$

317 The trailing edge thickness strongly affects the flow structure and correspondingly the

318 aerodynamic performance. For DU 91-W2-250_6 shown in Figure 11, the boundary layer flow is 
more stable as compared to the original airfoil DU 91-W2-250. Enlarging the trailing edge thickness

320 reduces the slope of airfoil profile at both sides and then helps to reduce the adverse pressure

321 gradient $\left.{ }^{4,}, 7,11\right]$. Therefore, eddies in the boundary layer of DU 91-W2-250_6 are smaller than that of

322 DU 91-W2-250 at the same angle of attack. For blunt airfoils at small angles of attack, e.g., $\alpha=0^{\circ}$, a

323 Kármán vortex shedding is caused by flow separation at the blunt trailing edge. This separation is

324 gradually merged into the boundary layer separation with the increase of angle of attack until the

325 airfoil stalls when a large boundary layer separation dominates the flow in the wake. Different form

326 the transient flow field, the averaged flow field in Figure 12 shows that there is no obvious

327 separation at $\alpha=0^{\circ}$ and at $\alpha=10^{\circ}$ on the suction surface of DU 91-W2-250_6.

328 As for the airfoil model DU 91-W2-250_10, the instantaneous flow structure in Figure 11 shows

329 that separation bubbles return to the boundary layer at $\alpha=0^{\circ}$ as compared to DU 91-W2-250_6

330 although the trailing edge thickness of DU 91-W2-250_10 is larger. The averaged flow field in

331 Figure 12 shows the same phenomenon with the instantaneous flow pattern for this airfoil model. It

332 shows that too large trailing edge thickness may play a negative role which brings the separation

333 bubble back to the boundary layer.

334 For higher angles of attack, as shown in Figure 13, the flow pattern in instantaneous flow field is

335 significantly different from in time-averaged flow field. The averaging smoothes out small

336 separation eddies or merges them into a thin separation bubble. Even after stall the separation

337 vortex seems smaller than in the instantaneous flow pattern. 


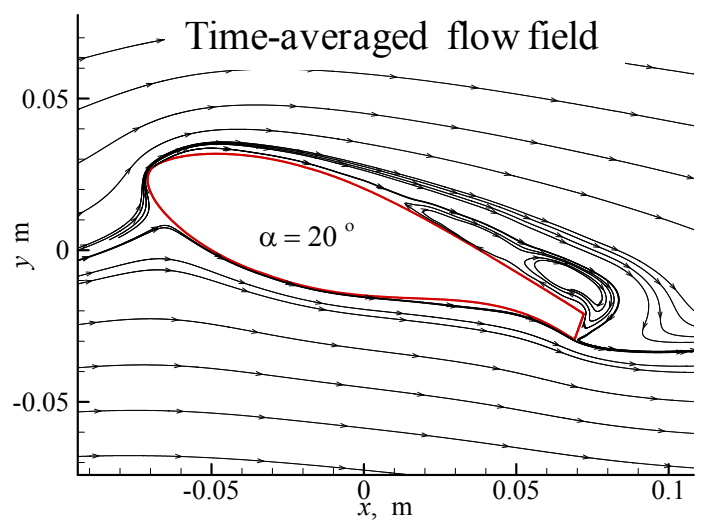

Figure 13 Flow pattern at a high angle of attack of $20^{\circ}, \mathrm{DU} 91-\mathrm{W} 2-250 \_6$ at $\operatorname{Re}=10^{5}$

\subsubsection{Spectrum characteristics of the velocity in boundary layer}
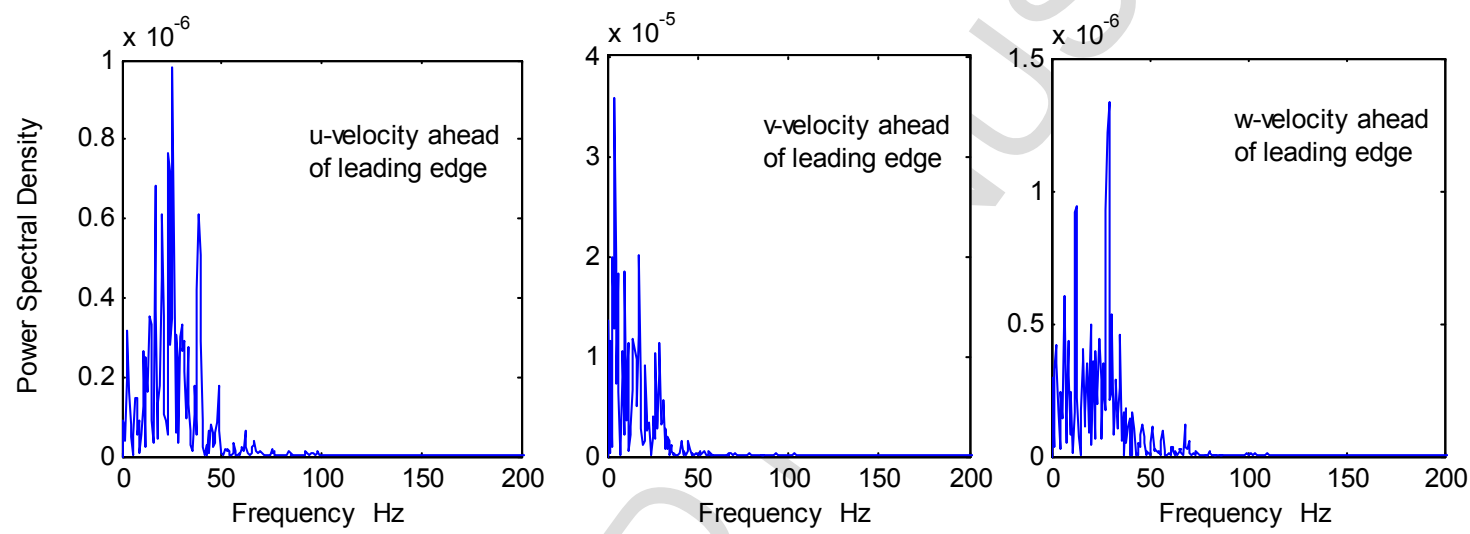

Figure 14 Spectra of velocity components at $0.24 c$ ahead of the leading edge, DU 91-W2-250_6
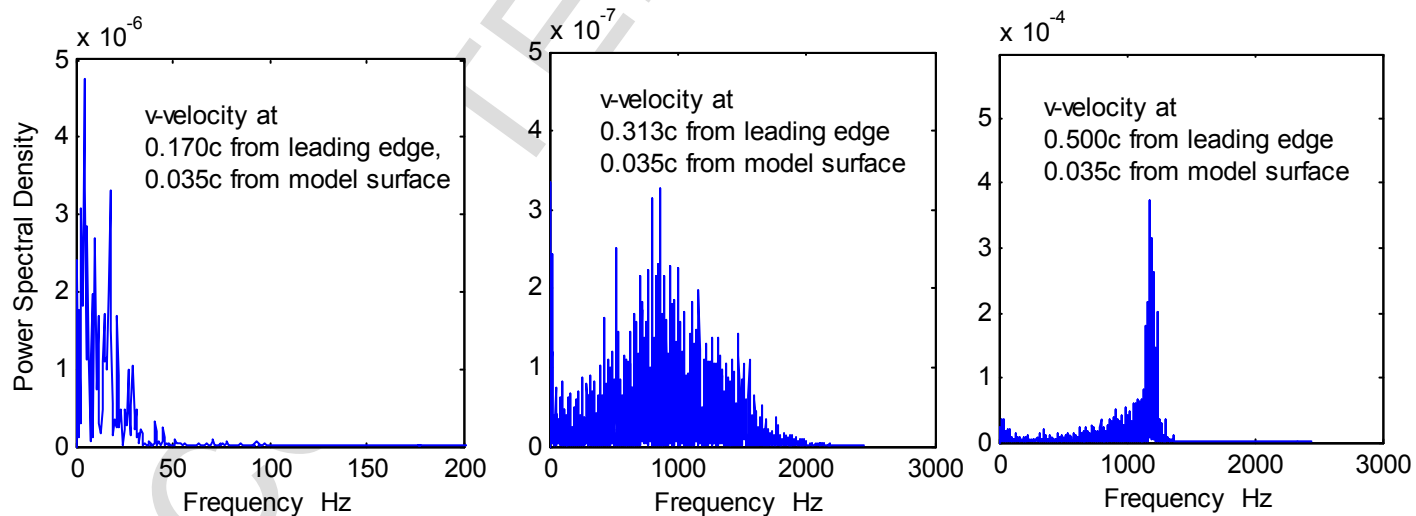

Figure 15 Spectra of $y$-velocities in the boundary layer, DU 91-W2-250_6

Ahead of the leading edge, the fluctuation of velocities is dominated by the low frequency vibration, which is less than $50 \mathrm{~Hz}$, as shown in Figure 14. It shows that the vibration in the ydirection (v) is stronger than that in the other two directions. There is a peak (about $25 \mathrm{~Hz}$ ) in the $\mathrm{x}$ direction $(\mathrm{u})$ and $\mathrm{z}$-direction $(\mathrm{w})$. This fluctuation presents in the boundary layer nearby the leading 
349 edge and will develop into larger vibrations with higher frequencies, as shown in Figure 15. The

350 peak frequency increases to about $1000 \mathrm{~Hz}$ at $0.313 c, 0.5 c$, and $0.035 c$ from the model surface.

351 Meanwhile, the PSD of $v$ increases from $10^{\wedge}-7$ to $10^{\wedge}-4$ in magnitude. The unsteadiness of the

352 vibrations increases greatly with the development of boundary layer implying the evolution of

353 waves in the boundary layer. The development of these waves agrees well with the description of

354 T-S instability when the boundary layer develops to turbulent flow from laminar flow ${ }^{[43,}{ }^{44]}$.

355 Moreover, the fraction factor on the upper airfoil surface abruptly increases at $0.32 \sim 0.33 c$,

356 indicating that the transition presents near the monitored point at $0.313 c$.

357 4.2.3 Spanwise modes of velocity in boundary layer

358 In order to examine the velocity distributions near the leading edge in the boundary layer, the

359 flow field is simulated based on DU 91-W2-250_6 after 6 seconds of calculation. Instantaneous

360 velocities on a spanwise line at $5.3 \% c$ near the leading edge on the suction surface were recorded

361 every 0.004 s, i.e., 40 iterations. Figure 16 shows the velocity distributions at $6.004 \mathrm{~s}$, in which the

362 velocities in the $z$-direction and $y$-direction are transformed into normal and tangential velocities

363 respect to the airfoil surface because they represent the boundary layer flow better than $v$ and $w$. It

364 shows that the velocity distributions are not uniform but vary in the spanwise direction. The

365 maximum amplitude of normal velocity is about $0.5 \%$ of the average velocity; and, the maximum

366 amplitude of tangential velocity is about $0.06 \%$ of the average velocity. The spanwise velocity

367 shows like a sinusoidal distribution with small fluctuations. The results show that in the viscous

368 boundary layer the velocity basically keeps two-dimensional characteristics with very small 


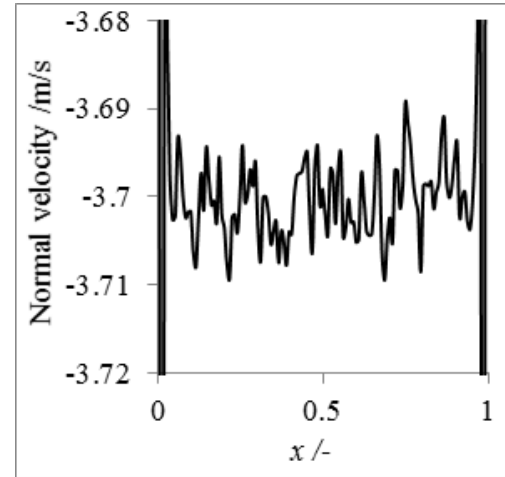

a)

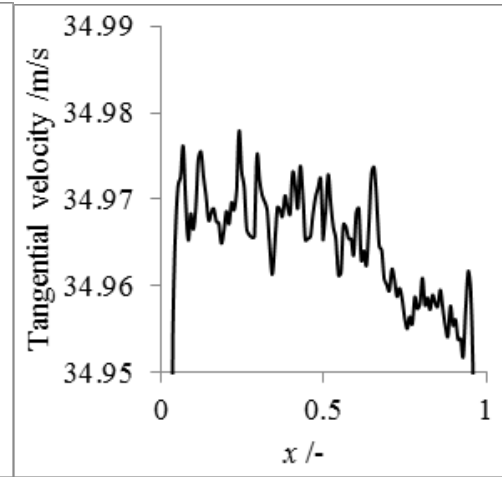

b)

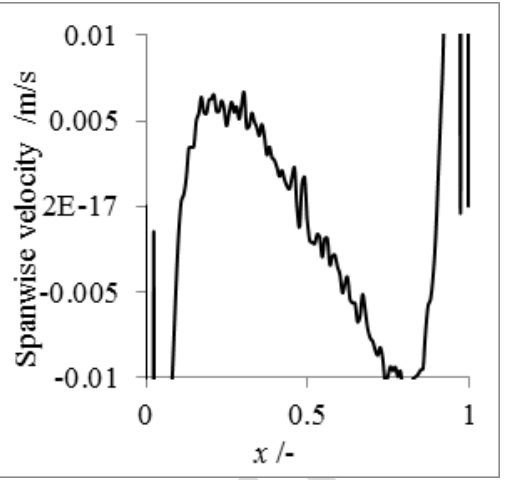

c)

Figure 16 Velocity distributions at $6.004 \mathrm{~s}$ and $x / c=5.3 \% \mathrm{c}$ near the leading edge, the span dimension is normalized by the width of span: a) Normal velocity; b) Tangential velocity; c) Spanwise velocity

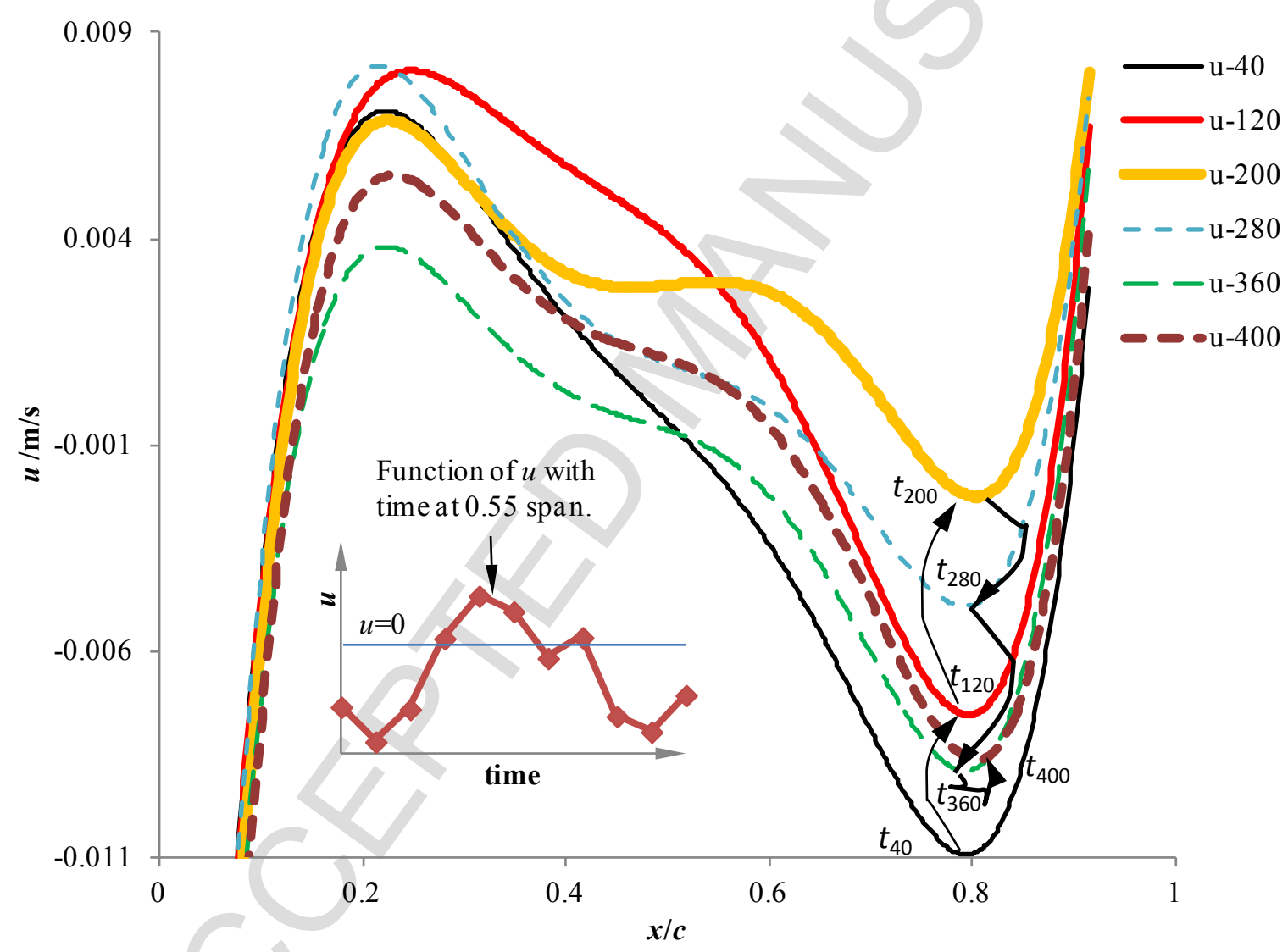

Figure 17 Spanwise velocity distributions along the span, at $5.3 \% \mathrm{c}$ from the leading edge

To further study the variation of flow structures, the $x$-velocity distributions at different times are fitted and plotted in Figure 17. The integer numbers in the legend are the iteration steps. For example, $\mathrm{u}-40$ is representative of velocities recorded at iteration 40 , i.e., after $0.004 \mathrm{~s}$. The variation 

from $\mathrm{u}-40$ to $\mathrm{u}-200$, the peak of fitting curves varies slightly but the valley increases a lot. From $\mathrm{u}$ -

381200 to u-280 the valley returns to decrease on contrary to the peak at this time. With time going on

382 the valley keeps decreasing as well as the peak at u-360. At u-400 the velocity distribution goes back

383 again to increase the valley and the peak as before. The velocity in the $x$-direction is not uniform in

384 space and varies with time, indicating that boundary layer is unstable. The authors consider it as a

385 low frequency variation because in the simulation period the variation of direction only changes

386 two times oppositely. The frequency may be around $25 \mathrm{~Hz}$ estimated from the total simulation

387 time. On the other hand, a low characteristic frequency is found in the spectra of forces and

388 velocities near the leading edge in Figure 9 and Figure 15. That should be the reflection of non-

389 uniformity and instability of the boundary layer.
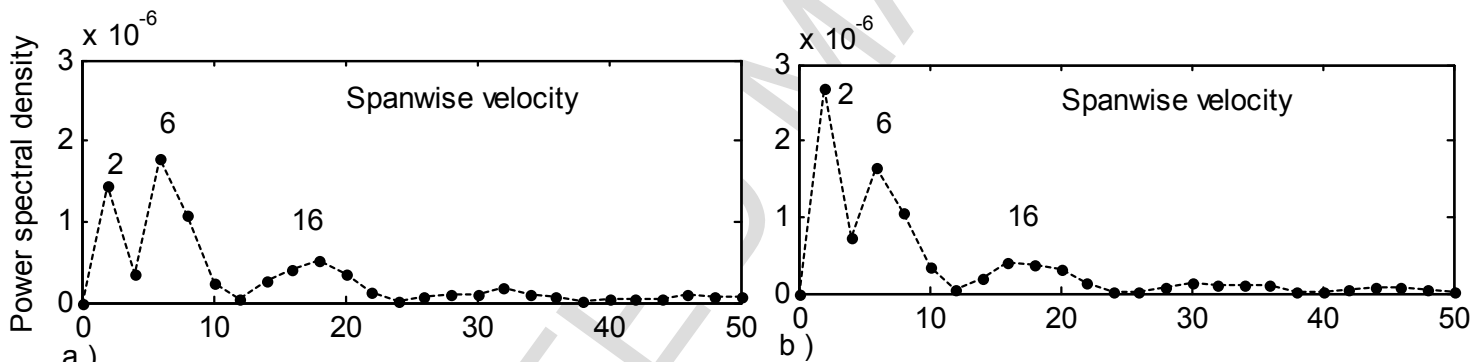

a )
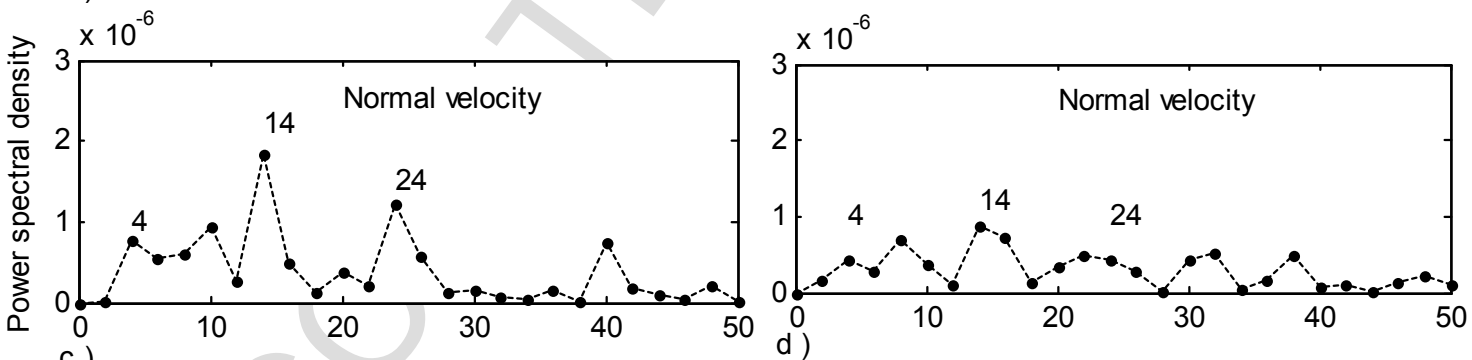

c )
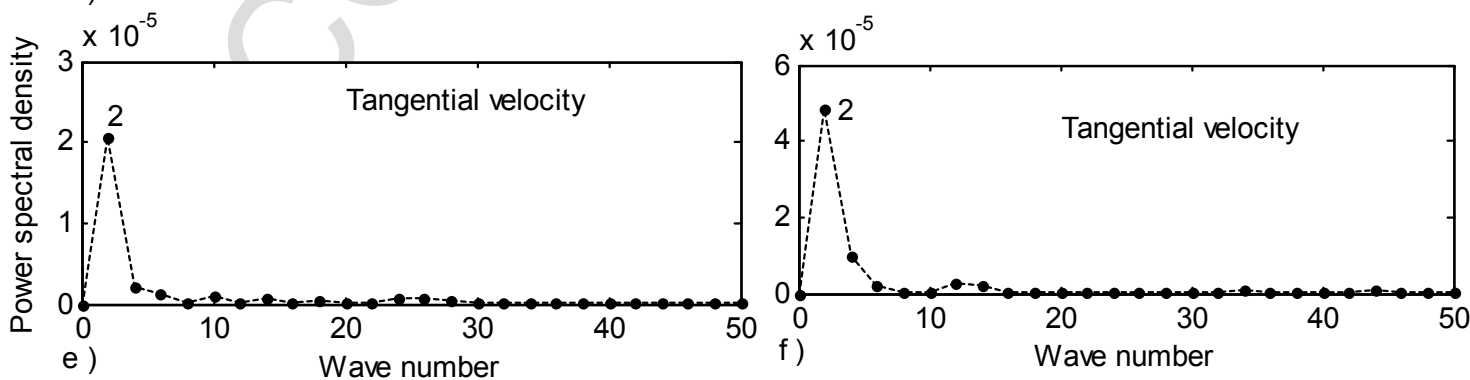
e ) Wave number

Figure 18 Power spectral density in wavenumber domain, the left column is at time iteration 200 and the 
By making a spatial FFT we get a power spectral density in wavenumber domain, as shown in

394 Figure 18. The spatial sample step is calculated by the spanwise grid step, which is in averaged

395 distribution. Figure 18 shows that the boundary layer instability is dominated by long waves with a

396 small wavenumber. The dominant wavenumbers in the spanwise, normal, and tangential directions

397 are 2 (6 at some time), 14, and 2, respectively. Because the span of the airfoil model is $0.5 \mathrm{~m}$, the

398 minimum wavenumber that can be recognized is $2 \mathrm{~m}^{-1}$. As shown in Figure $16 \mathrm{~b}$ ), the longest wave

399 in the tangential velocity is not intact, but it is still taken as an intact wave with wavenumber 2 . On

400 the other hand, the spanwise velocity distribution contains an intact wave of wavenumber 2 . This

401 result provides an additional evidence that the spanwise variation of the boundary layer contains a 402 dominant frequency of about $25 \mathrm{~Hz}$.

403 Due to the effect of the boundary layer instability, the dominant wave of the spanwise velocity

404 distribution varies with time. At some specific time, the wave of wavenumber 6 has a larger energy

405 than the wave of wavenumber 2 and then dominates the spanwise flow. Conclusively, long waves

406 of velocity distribution show a low frequency fluctuation of velocity in the boundary layer and

407 dominate the instability in the boundary layer.

\section{5. Conclusions}

The LES method has been applied to investigate unsteady aerodynamic performance of blunt

410 wind turbine airfoils. The experimental data at the same Reynolds number is used to validate the

411 LES method including comparisons of aerodynamic forces, pressure distributions, and dominate

412 frequency in the wake. The key points of this paper are: 1) comparison of aerodynamic

413 unsteadiness between the Exp. and LES simulation; 2) presenting separation bubbles in the

414 boundary layer affected by the trailing edge thickness; 3) presenting the boundary layer transition 
process on blunt airfoils; 4) showing the unsteadiness of boundary layer of blunt airfoils in the spanwise direction.

The aerodynamic performance of blunt airfoils is highly unsteady as well as velocities in the wake region. FFT on forces and velocities shows that the higher characteristic frequency is caused by vortex shedding, which is broadband as shown in the results of both LES and experiment. The peak frequencies of lifts in the band are about $450 \mathrm{~Hz}$ and $318 \mathrm{~Hz}$, respectively, for DU 91-W2-250_6 and DU 91-W2-250_10 at $\alpha=0^{\circ}$ and $v=30 \mathrm{~m} / \mathrm{s}$ when the chord length is $0.15 \mathrm{~m}$. Moreover, the results show that the frequency of aerodynamic forces depends on the vortex shedding but the peak frequencies may be slightly different between forces and monitored velocities. The trailing edge thickness has a strong effect on the spreading of vortex in the wake. The peak frequency can be found at $3.4 c$ in the wake of DU 91-W2-250_10 but disappears at $2.3 c$ in the wake of DU 91-W2250_6. Therefore, large shedding vortices spread farther downstream than small vortices in the wake.

Boundary layer instability has been investigated in three aspects including boundary layer separation, spectrum characteristics of velocity, and spanwise modes of velocity. First, the boundary layer of the original airfoil undergoes a serious separation even at zero angle of attack due to the low Reynolds number. The separation bubble moves towards the leading edge with the increase of angle of attack on the suction surface, while opposite on the pressure surface. Enlarging the trailing edge thickness can smooth the separation but a too much trailing edge gap plays weaker effects on smoothing the separation due to the increase of base pressure. Second, the spectral characteristics of velocity at special locations ahead of the leading edge and in the boundary layer show the instability of the boundary layer. The characteristic frequencies are about $25 \mathrm{~Hz}$ at the position ahead of the leading edge and in the boundary layer near the leading edge. With the development of boundary layer, the low frequency unsteady flow develops into a high frequency unsteady flow, which is in agreement with the development of T-S waves that lead to laminar-turbulent transition inboundary layer flows. Finally, an examination of spanwise modes of 
velocity shows an instability of boundary layer in the spatial domain. Velocity distributions along boundary layer. The boundary layer instability is from the low frequency unsteadiness judging from the development of spanwise distributions of velocities and dominant wavenumbers. project No.51776204 and Research Equipment Development Project of Chinese Academy of Sciences YZ201513. The authors acknowledge Yaru Ren, Jingyan Bai and other participants of the program and their contributions. is directed by Wen Zhong Shen. G. Wang analyzed the data and helped to revise the paper.

\section{References}

451 [1] Wang L., Liu X., Kolios A., "State of the art in the aeroelasticity of wind turbine blades: Aeroelastic modelling," Renewable E Sustainable Energy Reviews, Vo. 64, 2016, pp. 195-210.

[2] Jackson K., Zuteck M., Van Dam C. P., Standish K., and Berry D., “Innovative Design Approaches for Large Wind Turbine Blades," Wind Energy, Vol. 8, No. 2, 2005, pp. 141-171.

[4] Standish K. J., and Van Dam C. P., “Aerodynamic Analysis of Blunt Trailing Edge Airfoils,” Journal of Solar Energy Engineering, Vol. 125, No. 4, 2003, pp. 479-487.

[5] Göçmen T., Özerdem B., “Airfoil optimization for noise emission problem and aerodynamic performance criterion on small scale wind turbines," Energy, Vol. 46, No. 1, 2012, pp. 62-71. 

Applications," NASA CR-180803, 1987.

[8] Sato J., and Sunada Y., "Experimental Research on Blunt Trailing-Edge Airfoil Sections at Low Reynolds Numbers," AIAA Journal, Vol. 33, No. 11, 1995, pp. 2001-2005.

[9] Matsunosuke I., Kazuo A., Keiji K., and Yarii T., "Lift Characteristic of Blunt Trailing Edge Aerofoils Vol. 45, No. 516, 1997, pp. 62-66.

[10] Standish K. J., and Van Dam C. P., “Aerodynamic Analysis of Blunt Trailing Edge Airfoils," Journal of Solar Energy Engineering, Vol. 125, No. 4, 2003, pp. 479-487.

[11] Baker J. P., Mayda E., and Van Dam C. P., “Experimental Analysis of Thick Blunt Trailing-Edge Wind Turbine Airfoils," Journal of solar energy engineering, Vol. 128, No. 4, 2006, pp. 422-431.

[12] Chao D. and Van Dam C. P., "Computational Aerodynamic Analysis of a Blunt Trailing-Edge Airfoil Modification to the NREL Phase VI Rotor," Wind Energy, Vol. 10, No. 6, 2007, pp. 529-550.

[13] Van Dam C. P., Kahn D. L., and Berg D. E., “Trailing Edge Modifications for Flatback Airfoils,” U.S. Sandia National Laboratories, Rept. SAND2008-1781, Albuquerque, California, Mar. 2008.

[14] Baker J. P., Van Dam C. P., and Gilbert B. L., “Flatback Airfoil Wind Tunnel Experiment,” U.S. Sandia National Laboratories, Rept. SAND2008-2008, Albuquerque, California, Apr. 2008.

[15] Baker J. P., "Drag Reduction of a Blunt Trailing-Edge Airfoil," Ph. D. Dissertation, University of California, Davis, 2009. 
486

[17] Van Dam C. P., Cooperman A., McLennan A., Chow R., and Baker J., “Thick Airfoils with Blunt Trailing Edge for Wind Turbine Blades," ASME Turbo Expo 2010: Power for Land, Sea, and Air, ASME, Glasgow, UK, 2010. GT2010-23786.

[18] Chow R. and Van Dam C. P., “Computational Investigations of Blunt Trailing-Edge and Twist Modifications to the Inboard Region of the NREL 5 MW Rotor," Wind Energy, Vol. 16, No. 3, 2013, pp. 445-458.

[19] Tiantian Zhang, Wei Huang, Zhenguo Wang. et al. A study of airfoil parameterization, modeling, and optimization based on the computational fluid dynamics method. J. Zhejiang Univ. Sci. A (2016) 17: 632.

[20] Christopher S., Stephanie T., and Earl P. N. D., “Computational Fluid Dynamics of Flatback Airfoils for Wind Turbine Applications," 44th AIAA Aerospace Sciences Meeting and Exhibit, American Institute of Aeronautics and Astronautics, Reno, Nevada, 2006. AIAA 2006-194.

doi:10.2514/6.2006-194

[21] Yang K., Zhang L., and Xu J., “Simulation of Aerodynamic Performance Affected by Vortex Generators on Blunt Trailing-Edge Airfoils," Science in China Series E: Technological Sciences, Vol. 53, No. 1, 2010, pp. 17.

[22] Murcia J. P., and Pinilla Á., “CFD Analysis of Blunt Trailing Edge Airfoils Obtained with Several Modification Methods," Revista de Ingeniería, No. 33, 2011, pp. 14-24.

[23] Chen X., and Agarwal R., “Optimization of Flatback Airfoils for Wind-Turbine Blades Using a Genetic Algorithm," Journal of Aircraft, Vol. 49, No. 2, 2012, pp. 622-629.

[24] Lee S. G., Park S. J., Lee K. S., Chung C., “Performance Prediction of NREL (National Renewable Energy Laboratory) Phase VI Blade Adopting Blunt Trailing Edge Airfoil," Energy, Vol. 47, No. 1, 2012, pp. 47-61. 
[25] Schreck S., Fingersh L., "Rotational augmentation on a 2.3-MW rotor blade with thick flatback airfoil cross sections," 51st AIAA Aerospace Sciences Meeting including the New Horizons Forum and Aerospace Exposition, American Institute of Aeronautics and Astronautics, Grapevine, Texas, 2013. AIAA 2013-0915.

$$
\text { DOI: 10.2514/6.2013-915 }
$$

[26] El-Gammal M., and Hangan H., “Three-Dimensional Wake Dynamics of a Blunt and Divergent Trailing Edge Airfoil," Experiments in Fluids, Vol.44, No. 5, 2008, pp.705-717.

[27] Zhang L., Yang K., Xu J., Zhang M., and Bai J., “Unsteady Aerodynamic Performance and Mechanism of Blunt Trailing-Edge Airfoils," Journal of Engineering Thermophysics, Vol. 32, No. 3, 2011, pp. 387-390.

[28] Xu H., Shen W., Zhu W., Yang H., and Liu C., “Aerodynamic Analysis of Trailing Edge Enlarged Wind Turbine Airfoils," Journal of Physics: Conference Series, Vol. 524, No. 1, IOP Publishing, 2014, p.012010. DOI: $10.1088 / 1742-6596 / 524 / 1 / 012010$

[29] Bangga G. S. T. A., Lutz T., Krämer E., “Numerical investigation of unsteady aerodynamic effects on thick flatback airfoils," German Wind Energy Conference 12, DEWI, Bremen, Germany, 2015.

[30] Michelsen J., “Basis3d - A Platform for Development of Multiblock PDE Solvers,” Ph.D. Dissertation, Department of Fluid Mechanics, Technical University of Denmark, 1992. Technical Note AFM92-05.

[31] Sørensen N., "General Purpose Flow Solver Applied to Flow Over Hills," Ph.D. Dissertation, Risø National Laboratory for Sustainable Energy, Technical University of Denmark, 1995.

[32] Shen W. Z., Michelsen J. A., and Sørensen J. N., “An Improved Rhie-Chow Interpolation for Unsteady Flow Computations," AIAA Journal, Vol. 39, No. 12, 2001, pp. 2406-2409.

[33] Shen W. Z., Michelsen J. A. Sørensen N. N., and Sørensen J. N., “An improved SIMPLEC Method on Collocated Grids for Steady and Unsteady Flow Computations," Numerical Heat Transfer, Vol. 43, No. 3, Part. B, 2003, pp. 221-239. 
529

[34] Wei Huang, Shibin Li, Li Yan, et al. Performance evaluation and parametric analysis on cantilevered ramp injector in supersonic flows. Acta Astronautica, 2013, 84: 141-152.

[35] Wei Huang, Weidong Liu, Shibin Li, et al. Influences of the turbulence model and the slot width on the transverse slot injection flow field in supersonic flows. Acta Astonautica, 2012, 73: 1-9.

[36] Wei Huang, Jianguo Tan, Jun Liu, et al. Mixing augmentation induced by the interaction between the oblique shock wave and a sonic hydrogen jet in supersonic flows. Acta Astronautica, 2015, 117: 142-152.

[37] Shen W. Z., Zhu W., and Sørensen J. N., "Aeroacoustic Computations for Turbulent Airfoil Flows," AIAA Journal, Vol. 47, No. 6, 2009, pp. 1518-1527.

[38] Timmer W. A., and van Rooij R. P. J. O. M., “Summary of the Delft University Wind Turbine Dedicated Airfoils," Journal of Solar Energy engineering, Vol. 125, No. 4, 2003, pp. 488-496.

DOI: $10.1115 / 1.1626129$

[39] Clara M. V., Martin O. L. H., Meyer K. E., and Fuglsang P., “Evaluation of the Performance of Vortex Generators on the DU 91-W2-250 Profile Using Stereoscopic PIV," Journal of Systemics, Cybernetics and Informatics, Vol. 7, No. 3, 2009, pp. 92-96.

[40] Drela M., “XFOIL: an analysis and design system for low Reynolds number airfoils,” Low Reynolds Number Aerodynamics, Springer, 1989, pp. 1-12.

[41] Anderson J. D., Fundamentals of Aerodynamics, $2^{\text {nd }}$ ed., McGraw-Hill, New York, 1991, Chaps. 4, p. 272.

[42] Huang R. F., and Lin C. L., “Vortex Shedding and Shear-Layer Instability of Wing at Low-Reynolds Numbers," AIAA Journal, Vol. 33, No. 8, 1995, pp. 1398-1403.

doi: $10.2514 / 3.12561$

[43] Mayle R. E., “The role of laminar-turbulent transition in gas turbines engines,” Journal of Turbomachinery, Vol. 113, No. 11, 1991, pp. 509-536. 
551 [44] Morkovin M. V., Reshotko E., and Herbert T., “Transition in open flow systems-A reassessment," Bulletin 
1. Comparison of unsteady aerodynamics of blunt airfoils Between Exp. and LES

2. The frequency of lift is characterized by broadband and depends on vortex shedding

3. Presenting the effect of trailing edge size on separation bubbles in boundary layer

4. Presenting the boundary layer transition process on blunt airfoils

5. Unstable boundary layer in spanwise is characterized by low frequent wave 